\title{
Demonstration of Shape Memory and Superelastic Effects of Nitinol Alloys
}

\section{Dr. Mohamed Samir Hefzy, The University of Toledo}

Mohamed Samir Hefzy served as the Associate Dean of Graduate Studies and Research Administration of the College of Engineering (COE) at The University of Toledo (UT) for 14 years from 2004 until January 2018. He is a tenured Professor of Mechanical, Industrial and Manufacturing Engineering (MIME) and served as Graduate Program Director of the MIME department from August 2018 and from 2000 to 2007, and also was the first to hold that position during the 1994-95 academic year. Additionally, he serves as the Director of the COE Biomechanics and Assistive Technology Laboratory at UT. He has been on the faculty of The UT since 1987. He graduated from Cairo University, Egypt, with a B.E. (Honors) in Civil Engineering in 1972, and a B.Sc. in Mathematics from Ain-Shams University in 1974. He earned his M.S. in Aerospace Engineering in 1977 and his Ph.D. in Applied Mechanics in 1981, both from The University of Cincinnati. He then received training as a Postdoctoral Research Associate for two years in the Department of Orthopedic Surgery at The University of Cincinnati's College of Medicine. In 1983, Dr. Hefzy joined the faculty of Grand Valley State University in Allendale, Michigan as their first engineering faculty. He then returned to the University of Cincinnati as a Research Assistant Professor in 1985.

In December 2003, Dr. Hefzy was elevated to the Grade of American Society of Mechanical Engineers (ASME) Fellow in recognition of his outstanding contributions to research and development, to education and leadership in the Engineering Profession. Dr. Hefzy has published with his students more than 40 peer reviewed journal papers and 100 peer reviewed national and international conference papers, and coauthored more than 19 book chapters in his research areas: Orthopedic Biomechanics and Assistive Technology. Dr. Hefzy has secured more than $\$ 5$ million in funding as a PI, CO-PI, and CI to support his research program, with sponsors including the OBOR, the NSF and the NIH. He has supervised two postdoctoral fellows and has served as primary graduate advisor to more than 30 masters and doctoral students. In addition, he has supervised more than 130 undergraduate senior design projects at UT as part of his community engagement and service learning activities..

Dr. Hefzy is the recipient of many awards, including the 2011 Distinguished Service Award from the ASME, the Edith Rathbun Award for Excellence in Outreach and Engagement from The University of Toledo in 2006, the University of Toledo Outstanding Faculty Research Award in 2004 and the College of Engineering's Outstanding Teacher Award and the Outstanding Undergraduate Research Mentoring Award in 1999 and 2001, respectively. His engineering experience and familiarity with recent educational practices led to his selection by the ASME as a Mechanical Engineering Evaluator for the Accreditation Board for Engineering and Technology (ABET). At the national level, Dr. Hefzy has served two consecutive three-year terms as the Treasurer and member the ASME's Executive Committee of the Bioengineering Division (BED) (2010-2013 and 2007-2010). He has also served as a member at large on the ASME's Executive Committee of the BED from 1999 to 2002 and as Chair of the BioSolids Technical Committee of the BED from 2004-2007. He has also served a two-year term on the basic Engineering Group Operating Board (BEGOB) as a representative to the Committee on Administration and Finance of the ASME (2011-2013) and a two-year term (2013-2015) on BEGOB as a rep. to the strategic planning committee. He has also served as a judge for the ASME Scholarship Program's University applications from March from 2016 to 2018.

\section{Prof. Mohammad Elahinia, The University of Toledo}

Dr. Elahinia is a University Distinguished Professor in Engineering and Chair in the Mechanical, Industrial, and Manufacturing Engineering (MIME) Department at The University of Toledo. He graduated with his doctorate in Mechanical Engineering from Virginia Polytechnic Institute and State University in August 2004. After graduation, he joined the faculty of the Mechanical, Industrial, and Manufacturing Engineering Department, where he is the director for the Dynamic and Smart Systems Laboratory. He was promoted to the rank Associate Professor with tenure in 2010 and Professor in 2015. Dr. Elahinia's research interests are advance manufacturing, modeling, control, and design of smart materials with an 
emphasis on additive manufacturing of functional materials such as shape memory alloys for aerospace and biomedical application.

At UToledo he has served as an investigator on several funded projects with a total budget of more than $\$ 15$ million. These projects are funded by NSF, EPA, US Army, US DOT, Ohio Department of Development, Ohio Board of Regents, and the UT. Dr. Elahinia is a Fellow of the American Society of Mechanical Engineers. He has received several awards, including the University of Toledo 2019 Outstanding Teacher Award, Outstanding University of Toledo 2017 Faculty Research Award, ASME 2010 Adaptive Structures and Material Systems Gary Anderson Early Achievement Award, University of Toledo 2010 College of Engineering Faculty Excellence Award, University of Toledo 2006 Outstanding Young Faculty Research Award and Virginia Tech 2004 Torgersen Graduate Research Excellence Award.

Dr. Elahinia has also been active in translating research out of his laboratory. Three startup companies have been formed to commercialize three medical devices and technologies in the area of smart materials. These companies have raised more than $\$ 2$ million in external funding.

Dr. Elahinia has served as the major advisor for 45 graduate students (10 Ph.D. and 35 M.S.). Seven of his former students are assistant and associate professors at other universities. To disseminate his research findings, Dr. Elahinia and his students co-authored 3 books, 7 book chapters, and more than 100 journal papers. Dr. Elahinia has also been active and engaged in professional societies. In 2004 Dr. Elahinia was elected a member of the ASME/SPIE Adaptive Structures and Material Systems Branch under the Aerospace Division. He has since served in several other elected positions including the chair of the branch. This branch has more than 1500 members. Dr. Elahinia serves as an associate editor for four journals in his area of research: Smart Material Research, The Scientific World Journal, Journal of Intelligent Material Systems and Structures as well as the Journal of Shock and Vibration.

\section{Mr. Ahmadreza Jahadakbar, The University of Toledo \\ Mrs. Bethany Arn, The University of Toledo, MIME Department}

Graduate Assistant - Mechanical, Industrial, and Manufacturing Engineering Department, The University of Toledo. Biomechanics and Assistive Technologies Lab.

\section{Mohammadreza Nematollahi, University of Toledo}




\title{
DEMONSTRATION OF SHAPE MEMORY AND SUPERELASTIC EFFECTS OF NITINOL ALLOYS
}

\author{
Mohamed Samir Hefzy ${ }^{1}$, Ph.D., PE, ASME Fellow \\ Mohammad Elahinia, Ph.D., ASME Fellow \\ Ahmadreza Jahadakbar, Ph.D \\ Bethany Arn, M.S. \\ Mohammadreza Nematollahi, M.S.

\begin{abstract}
Biomechanics and Assistive Technology Lab. Dynamics and Smart Systems Lab. College of Engineering, University of Toledo, Toledo, Ohio 43606
\end{abstract} \\ Departments of Bioengineering and Mechanical, Industrial and Manufacturing Engineering
}

\begin{abstract}
One of the outcomes of the course entitled: "Experimental Methods in Orthopaedic Biomechanics" is for mechanical and bioengineering undergraduate and graduate students to learn the design and implementation of Nitinol (Nickel-titanium, NiTi) alloys. This is achieved by conducting two experiments to observe the shape memory and superelastic effects of NiTi alloys. The superelastic effect exhibits itself when a relatively high mechanical load is applied to the material at relatively high temperatures. In this condition the material recovers relatively high levels of deformation upon unloading. The shape memory effect is the material behavior after permanent deformation in response to temperature changes which leads to shape recovery. NiTi wires were tested in both experiments.
\end{abstract}

\section{Introduction}

The course entitled "Experimental Methods in Orthopaedic Biomechanics" is an elective course for senior undergraduate and graduate mechanical and bioengineering students at our university. In this course, the students perform a series of 10 laboratory experiments that demonstrate different concepts related to orthopaedic biomechanics. The goal of two of these experiments is to observe the behavior of shape memory alloys (SMAs) which are a unique class of materials with the ability to recover their shape. There is a growing body of evidence to show the effectiveness of modular teaching to bring advance topics to engineering course. In this paper we have incorporated a project-based learning (PBL) module into an advanced engineering course. This PBL module brings additional skills in areas of functional materials to bioengineering students that they would not otherwise receive. The PBL module that consists of lectures and laboratory experiments was seamlessly connected with the rest of the content of the course. This approach allowed us to create a low barrier way of adopting shape memory alloy by introducing advanced topics in the existing course $[1,2]$.

Nitinol (Nickel-titanium, NiTi) alloys are one of the most well-known and most used biocompatible SMAs. Shape memory alloy market (predominantly NiTi) is a growing market and is expected to arrive at $\$ 33.9$ billion market by 2027 . This is mainly due to the fact that Nitinol has widely being used in medical devices as the base material for transcatheter stent-graft systems, self-expanding stents, clot removal baskets, filter, as well as in various endoscopic and

\footnotetext{
${ }^{1}$ Corresponding author; Mohamed.hefzy@utoledo.edu
} 
interventional procedures. Over the past 10 years the growth in Nitinol market has increased with increase in the number of nitinol suppliers and is progressing rapidly, with increasing demand from medical device community [3-7]. Orthodontic wires made of Nitinol are getting more popular. Superelastic Nitinol make it easy to exert constant force on the teeth to move them to their desired locations. This enables less sessions needed to retighten the arch wire which is needed for conventional materials. Nitinol guidewires are good candidates to reach out to difficult places inside the body due to their flexibility compared to stainless steel. Nitinol wire was used to retract rectum during radiation therapy of pelvic tumors [4]. Nitinol has also been employed in the defense (special antennas, wire, harness and cable), automotive (sealing plugs and locking rings), and aerospace industries (locking rings, actuators and connectors for electronica and safety devices). Industrial applications such as couplings, actuators, sealing highpressure fuel passages, and commercial applications such as cellphone antennae and eyeglass frames have also used Nitinol as a key material. More recently with the advancement of additive manufacturing techniques for shape memory alloys, NiTi complex shape geometries can be 3D printed for a variety of applications. A stiff-matched bone fixation NiTi plate for mandibular reconstruction surgery was designed and 3 printed [5]. Adding porosity was the main key to modulate the stiffness to match the patient bone stiffness and layer wise fabrication using selective laser melting enabled the build of this complex geometry. Also, currently there are ongoing research on fabricating different type of lattice structures with NiTi powder for a variety of applications; from bone implants to light weight actuators [8-9].

NiTi has two thermomechanical stable phases, each with a different crystal structure and therefore different properties. One is the high temperature phase called austenite (A) and the other is the low temperature phase called martensite (M). The austenite phase is also called the parent phase, which means that the material is in a high-temperature environment with respect to the martensite phases. The martensite phase can exist in two forms: twinned martensite $\left(\mathrm{M}_{\mathrm{t}}\right)$, and detwinned or reoriented martensite $\left(\mathrm{M}_{\mathrm{d}}\right)$. The twinned and detwinned martensite phases occur in a low-temperature environment. There are four characteristic temperatures associated with the phase transformation between martensite and austenite which are martensitic start temperature $\left(\mathrm{M}_{\mathrm{s}}\right)$, martensitic finish temperature $\left(\mathrm{M}_{\mathrm{f}}\right)$, austenitic start temperature $\mathrm{A}_{\mathrm{s}}$ and austenitic finish temperature $A_{f}\left(M_{f}<M_{s}\right.$ and $\left.A_{s}<A_{f}\right)$. The transformation between austenite and martensite which can happen due to the temperature or load change is the basis for the super elasticity and shape memory properties [10].

The shape recovery ability of the NiTi is due to a phase transformation between the austenite and the martensitic phases in a reversible way due to temperature and/or load changes. It is recognized that:

- If the test temperature is higher than $\mathrm{A}_{\mathrm{f}}$ (austenite finish temperature), then NiTi exhibits superelastic behavior.

- If the test temperature is lower than $\mathrm{M}_{\mathrm{f}}$ (martensite finish temperature), then NiTi exhibits shape memory effects.

- Going from austenite to detwinned martensite and vice versa is due to loading.

- Going from austenite to twinned martensite and vice versa is due to temperature changes (cooling and heating)

- Going from twinned martensite to detwinned martensite is due to loading. 


\section{Experiment \# 1 - Superelastic effect}

Nitinol as a shape memory alloy exhibits two different behaviors: shape memory and superelastic effects. This experiment focuses on demonstrating the superelastic behavior, which is demonstrated by applying a sufficiently high mechanical load to the material in the austenite phase (test temperature is higher than the austenite finish temperature of the alloy). This leads to a stress-induced transformation to the detwinned martensite phase that creates a relatively large strain (about 6\%) which can be fully recovered by unloading.

The superelastic behavior of SMAs is associated with stress-induced transformation, which leads to strain generation during loading and subsequent strain recovery upon unloading at temperatures above $\mathrm{A}_{\mathrm{f}}$. A superelastic thermomechanical loading path generally starts at a sufficiently high temperature where stable austenite exists, then develops under an applied load to a state at which detwinned martensite is stable, and finally it returns to the austenitic phase when goes back to zero stress state as shown in Figure 1.

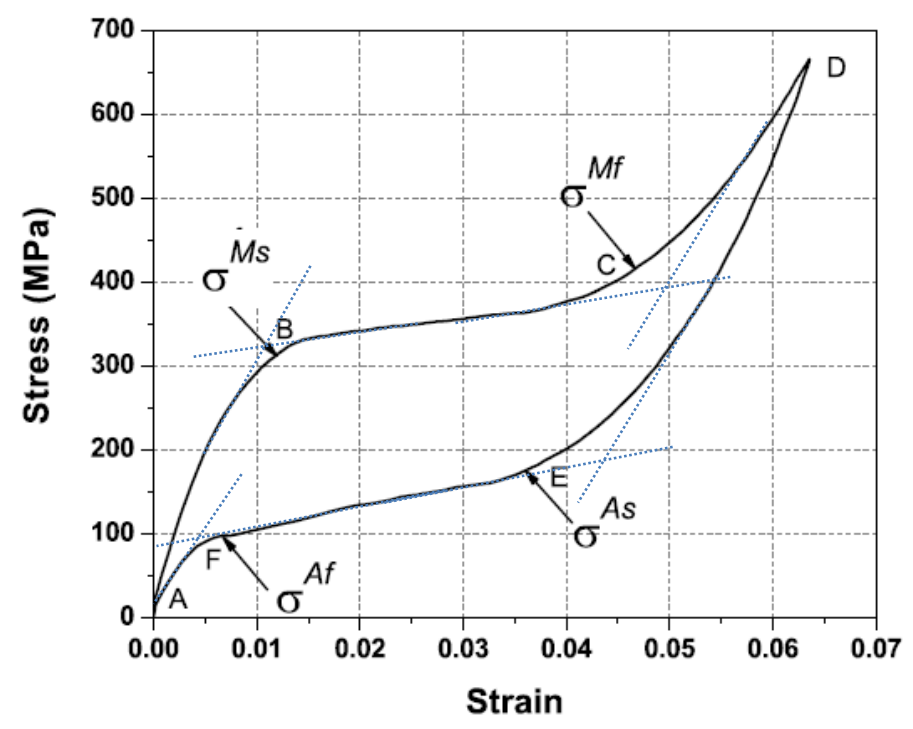

Fig.1 A typical SMA superelastic loading cycle

When a mechanical load is applied, the parent phase (austenite) undergoes elastic loading ( $\rightarrow$ B). At a specific load level, the stress reaches $\sigma_{\mathrm{Ms}}$ (the initiation of martensitic transformation) for the onset of transformation into detwinned martensite. Note that the stress-induced transformation from austenite to detwinned martensite is accompanied by the generation of large inelastic strains as shown in the stress strain diagram of Figure 1. The transformation proceeds $\left(\mathrm{B} \rightarrow \mathrm{C}\right.$ ), to the stress level $\sigma_{\mathrm{Mf}}$ (the final critical transformation stress) which indicates the end of the transformation. Further loading causes elastic deformation in the detwinned martensite phase. During unloading, after an initial elastic strain recovery, the material transforms back to austenite and the transformation starts at $\sigma_{\mathrm{As}}$ and completes at $\sigma_{\mathrm{Af}}(\mathrm{E} \rightarrow \mathrm{F})[11]$. The transformation between austenite and martensite leads to a temperature change in the NiTi which 
strongly depends on the strain rate [12]. These items are investigated in the first part of the experiment \#1.

A BOSE ElectroForce ${ }^{\circledR} 3330$ machine and an IR Camera (from Micro Epsilon) are used in this experiment. The BOSE machine allows the application of a tension force on a sample under a constant rate of elongation. Testing should be done in a displacement control mode. In this experiment, a displacement control mode was used where a maximum displacement of $\sim 1.8 \mathrm{~mm}$ is applied to the specimen as a specified strain rate. The IR camera can measure the surface temperature of the sample wire during loading and unloading. A NITI\#1 wire with 0.025 ", diameter, manufactured by FORT WAYNE METALS, Inc. from Indiana is used in this experiment.

Tension force was applied at two different strain rates: an isothermal loading at a rate of 0.005 $\mathrm{mm} / \mathrm{s}$ and a dynamic loading at a rate of $0.5 \mathrm{~mm} / \mathrm{s}$. The loading rate was set using the Wintest@7 software. In the beginning, the material is in the austenite phase. The external load causes a stress-induced transformation from Austenite to detwinned Martensite. The recoverable induced strain is much higher (about $8 \%$ ) than that of conventional materials. By unloading the material, it transforms back to Austenite and recovers its shape. The wire was trained at the high strain rate to stabilize the cyclic response. Load-displacement curves, stress-strain curves, and temperature changes in the wires were plotted and analyzed. Students were asked to identify one example of the application of superelastic wires and describe how it works and its advantages compared to traditional materials.

\section{Experiment \# 2 - Shape memory effect}

This demonstration focuses on the shape memory effect (SME). An increase in temperature can result in shape recovery even under some level of applied loads. Such characteristics of SMAs have made them a good candidate for sensing and actuation applications.

The phase transition from austenite to martensite is termed forward transformation. Under cooling, austenite begins to transform to twinned martensite at the martensitic start temperature $\left(\mathrm{M}_{\mathrm{s}}\right)$ and completes transformation to martensite at the martensitic finish temperature $\left(\mathrm{M}_{\mathrm{f}}\right)$ without load. At this stage, the transformation is complete and the material is fully in the twinned martensitic phase. When the martensitic phase transforms back to austenite, the transition is called reverse transformation. During heating, the reverse transformation initiates at the $\left(\mathrm{A}_{\mathrm{s}}\right)$ and the transformation is completed at the $\left(\mathrm{A}_{\mathrm{f}}\right)$.

Figure 2 shows the shape memory effect for a typical SMA wire, which also represents our demonstration process. The wire starts from the twinned martensite phase (point B) under room temperature (which means the room temperature is lower than $\mathrm{M}_{\mathrm{f}}$ ). When the twinned martensite is subjected to an applied stress that exceeds the detwinned start stress level $\left(\sigma_{s}\right)$, the transformation process from twinned martensite to detwinned martensite is initiated. Detwinning completes at the detwinned finish stress $\left(\sigma_{\mathrm{f}}\right)$. Continuing loading would cause elastic deformation of detwinned martensite (point $\mathrm{C}$ ). When the material is heated and cooled with a mechanical load produced by the weight, the phase transformation will occur directly between detwinned martensite and austenite and then back to detwinned martensite (process C to C to C" 
to $\mathrm{C}$ in Figure.3). After three cycles of heating and cooling, the deformed configuration is retained as the load is released (point D) and the wire is in detwinned martensite phase. Then voltage is applied on the wire again. During heating, when the temperature reaches $\mathrm{A}_{\mathrm{s}}$ (point $\mathrm{E}$ ), the material starts to transform from detwinned martensite to austenite. A subsequent heating of the SMA to a temperature above $\mathrm{A}_{\mathrm{f}}$ (point $\mathrm{F}$ ) will result in a complete phase transformation (from detwinned martensite to austenite) and shape recovery. Cooling back to room temperature below $\mathrm{M}_{\mathrm{f}}$ leads to the formation of twinned martensite again with no associated shape change observed (point B). This process is described as Shape Memory Effect (SME) [13].

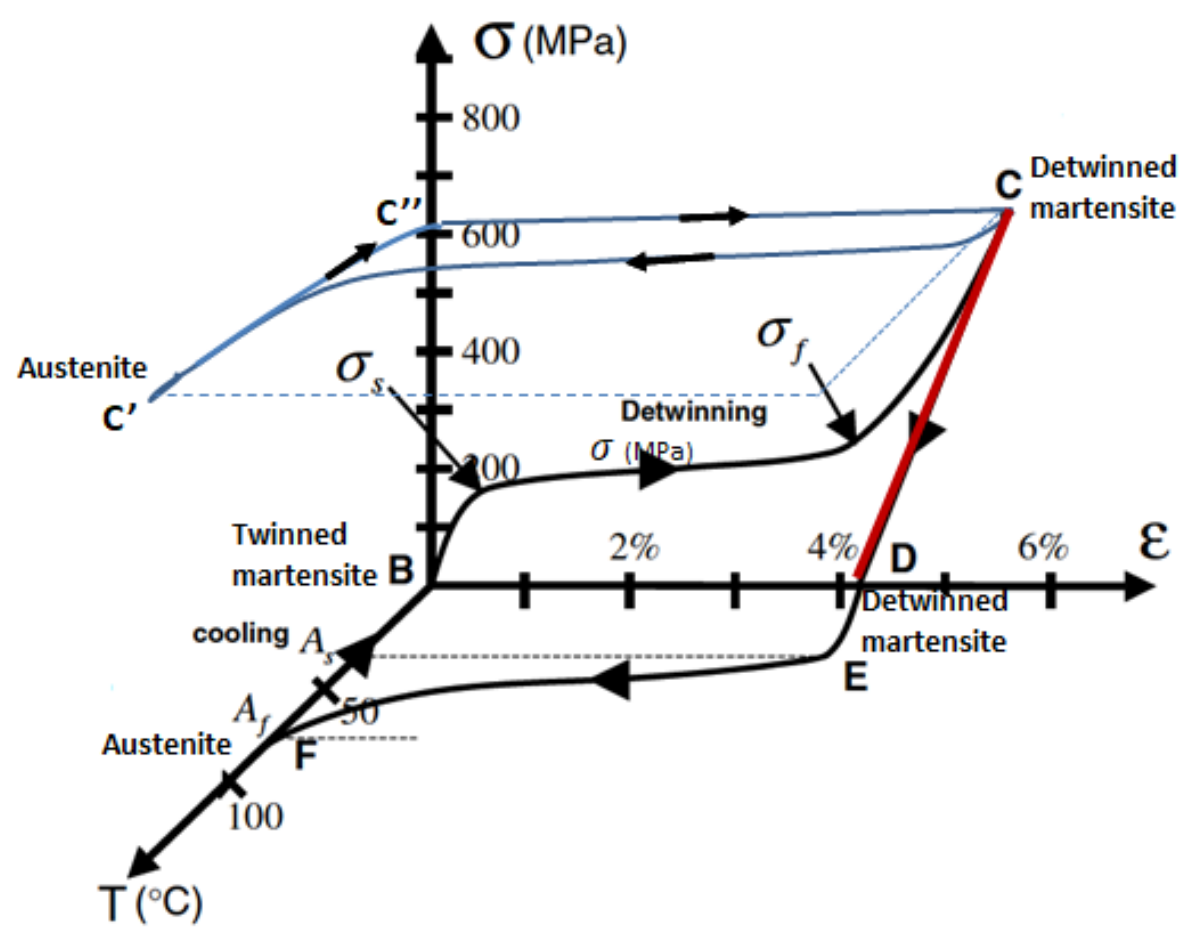

Figure 2

Stress-strain-temperature data exhibiting the shape memory effect for a typical NiTi SMA

A Flexinol actuator wire with a $250 \mu \mathrm{m}$ diameter, manufactured by DYNALLOY, Inc. from California is used for this demonstration. The setup is composed of an Agilent E3631A Triple Output DC Power Supply (6V/5A +/-25V/1A), a FLEXINOL® wire, a thermocouple, a laser sensor made by MICRO-OPTRONIC (Germany), an Arduino UNO board, a fan, and a weight (shown in Figures 3 and 4). Each is described as follows:

The E3631A Triple Output DC Power Supply - is controlled by the Arduino UNO to add or remove current depending on the thermocouple readings;

$>\quad$ The FLEXINOL® Wire - the SMA wire being utilized for SME properties; 
Thermocouple - regulates the temperature of the SMA wire to stay between $30^{\circ} \mathrm{C}$ and $100^{\circ} \mathrm{C}$;

$>$ The laser sensor - measures the activation range of the wire with contraction and relaxation;

Fan - enhances the cooling effect upon the wire;

$>\quad$ Weight - is used to exert a loading on the SMA wire.

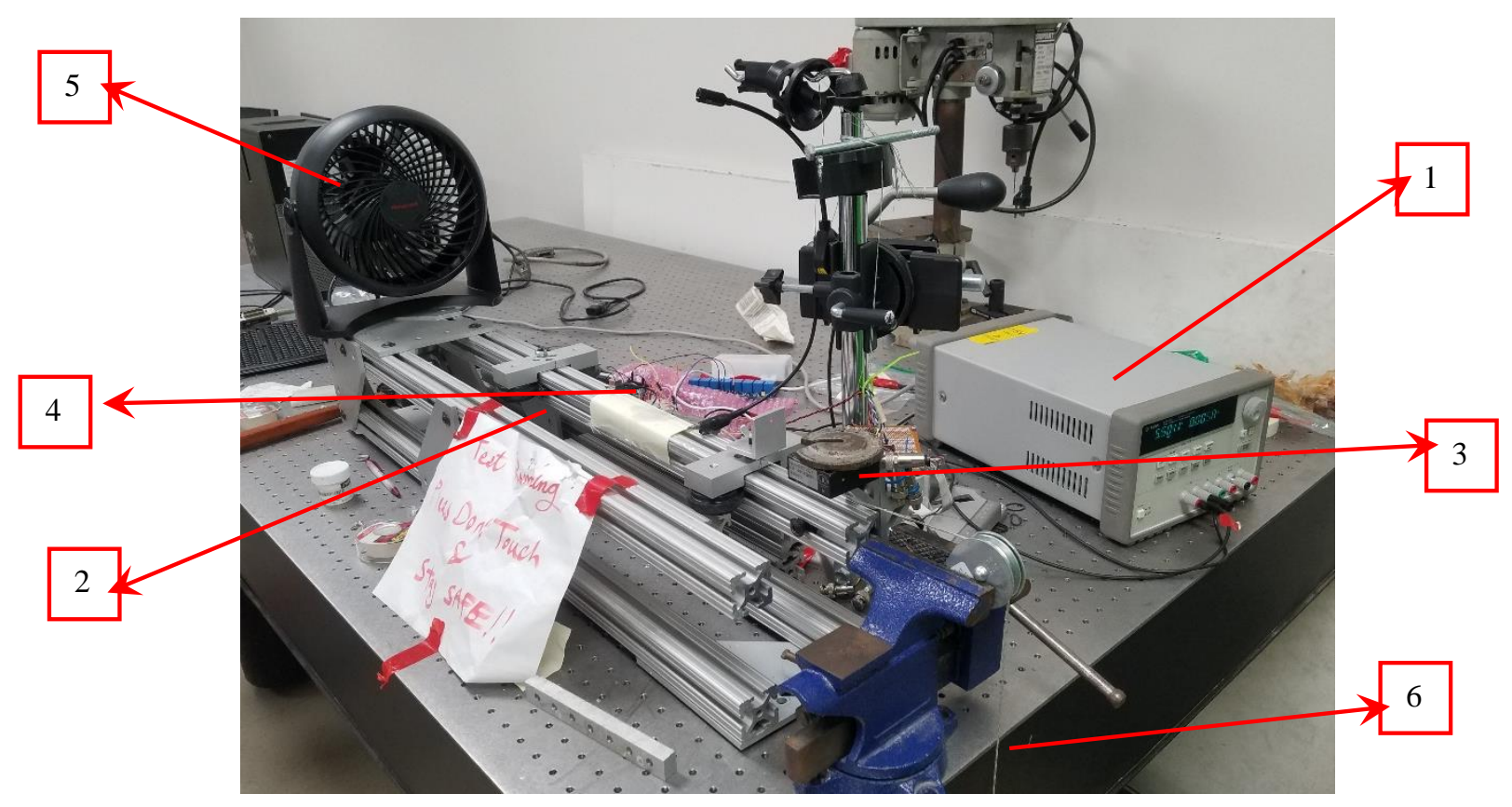

Figure 3. The demonstration system for a SMA wire: 1-DC Power Supply; 2-SMA Wire (FLEXINOL®) Setup with Thermocouple; 3-Laser Sensor; 4-Arduino UNO Board (slightly hidden); 5-Fan; 6-Weight (attached to wire off of screen).

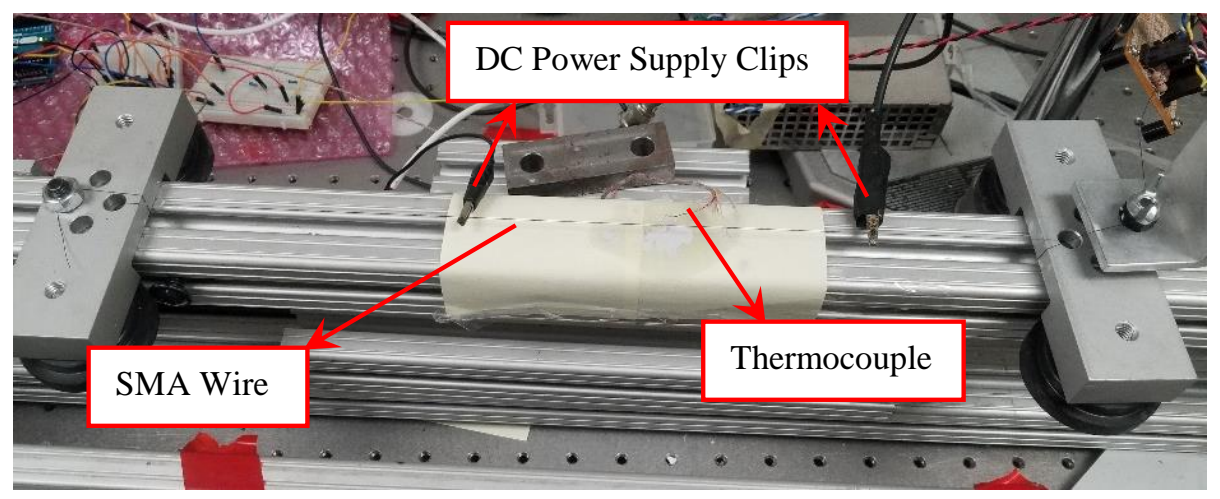

Fig.4 The SMA Wire Setup with DC Power Supply Clips and Thermocouple attached. 
The Arduino UNO board - allows the real time displacement communication between the laser sensor and the $\mathrm{PC}$, allows the real time temperature communication between the thermocouple and the PC, commands the power supply switch to turn on and off depending on the temperature readings, utilizes the Parallax Data Acquisition (PLXDAQ) Excel add-on;

In this experiment, the NiTi wire is initially in its twinned martensitic phase. It is then loaded by adding a $1 \mathrm{~kg}$ weight and transformed into the detwinned martensite phase. Current is then applied to the wire until the temperature reaches $100^{\circ} \mathrm{C}$ and then the current removed until the temperature decreased to $30^{\circ} \mathrm{C}$. (Going from $\mathrm{C}$ to $\mathrm{C}$ ' to $\mathrm{C}$ " and then back to $\mathrm{C}$ on the curves of Figure 2). The load is removed, and the material remains in its detwinned martensite phase.

Large residual strains (about 8\%) can also be observed after removing the load. The wire is then heated, which causes the material to transform back to the austenite phase, recovering a significant portion of the strains. When the heat is removed, the material returns to its original twinned martensite phase and the cycle can be repeated.

The experiment was repeated for three different loading levels. An Arduino board was used to command the power supply switch to turn on and off depending on the temperature, and to allow the real time temperature communication between the thermocouple and the PC. The Arduino board utilized the Parallax Data Acquisition Excel add-on for data acquisition.

Stress-strain curves were plotted. Students were asked to describe the phase that the SMA wire is in: 1) when the wire is on the table, before being installed; 2) after being installed on the setup with no weight added; 3) when weight is added but no current is applied; 4) when the wire temperature is at $100^{\circ} \mathrm{C}$ with the weight added; 5) when the wire temperature is at $30^{\circ} \mathrm{C}$ with the weight added; 6) when the wire is unloaded; 7) when the wire is unloaded and again a current is applied to increase the temperature to $100^{\circ} \mathrm{C} ; 8$ ) when the wire is finally cooled down. Students were also asked to identify one example of the application of the shape memory alloy (SMA) where the design is based on using the shape memory effect of the wire and describe briefly how the SMA wire works.

\section{Discussion}

This course, "Experimental Methods in Orthopaedic Biomechanics", consists of conducting ten experiments related to orthopaedic biomechanics where students work in groups. This course focuses on the following outcomes:

(a) ABET outcome 1: An ability to identify, formulate, and solve complex engineering problems by applying principles of engineering, science, and mathematics

(b) ABET outcome 3: An ability to communicate effectively with a range of audiences

(c) ABET outcome 5: An ability to function effectively on a team whose members together provide leadership, create a collaborative and inclusive environment, establish goals, plan tasks, and meet objectives 
(d) ABET outcome 6: an ability to develop and conduct appropriate experimentation, analyze and interpret data, and use engineering judgment to draw conclusions

The two experiments described in this paper focus on ABET outcomes 3, 5 and 6.

The first time this class was offered was in Spring 2015, the second time in Spring 2017 and the third time in Spring 2019. Seventeen students were enrolled in the class in 2015, eleven students in 2017 and seven students in 2019. All of the students were undergraduate students in bioengineering. There are many elective courses for graduate students to choose from in the departments of bioengineering and mechanical engineering at the University of Toledo. This may be the reason that there were zero graduate students over the past 5 years in this course that was designed for graduate and undergraduate students. Also, undergraduate enrollment appears to be dropping from 17 in 2015, to 11 in 2017, and to just 7 in 2019. However, enrollment is up to 10 during the ongoing spring 2020 semester. The reason for low enrollment is that this course is offered primarily for undergraduate bioengineering students. The curriculum is designed such that it is available to students in their senior year. Most of the senior students have seen some of the material covered in the course in previous classes. To address this issue, the department of bioengineering has decided to make this course a required course for their undergraduate students to provide them with an experience in experimental methods in orthopaedic biomechanics. Also, the required course will be taken by students in their sophomore year. It is thus expected to have a large increase in enrollment. The first cohort of bioengineering students that will take this required course started their program in fall 2019. They will thus take this course in spring 2021.

In 2015, the average grade obtained in the report for the first lab demonstrating the superelastic effect of the NiTi was 91.7 (out of 100) with the highest grade of 99.50 and the lowest grade 80.50. The average grade for the report for the second experiment was 88.7 with the highest grade of 96 and the lowest grade 82. In 2017, the average grade for the report of the first lab was 82.6 with the highest grade of 89.25 and the lowest grade 70.75 . The average grade for the report for the second experiment was 93.45 with the highest grade of 98.75 and the lowest grade 87.50. In 2019, the average grade obtained in the report for the first lab was 70 with the highest grade of 85 and the lowest grade 61.25. Six students (out of seven) submitted the lab report for the second experiment and the average grade was 79.8 (out of 100) with the highest grade of 94.75 and the lowest grade 69.00. These data show that the students submitted (on average) a better report for the second experiment (than that for the first experiment) which is harder to grasp.

The results of the graded reports indicate that the students were able to conduct experiments to characterize the mechanical properties of shape memory alloys. The students showed understanding of each behavior associated with SMAs; however the 2019 students showed one specific lack of understanding with each behavior. For the superelastic behavior, Experiment \# 1, all seven students had trouble grasping that Young's Modulus in austenite $\left(\mathrm{E}_{\mathrm{A}}\right)$ is always greater than the Young's Modulus in martensite $\left(\mathrm{E}_{\mathrm{M}}\right)$ - this was a calculation asked from the students when analyzing the stress-strain curves. This understanding would have allowed the students to check their results to ensure that the regions they were analyzing on the stress-strain curve were the correct regions. Additionally, in Experiment \# 2, depicting the shape memory effect, six out of the 2019 seven students showed a lack of understanding that as the temperature increased, the 
strain would decrease. After consulting the students that year, it was determined that this was due to a misunderstanding of the data processing required for the experiment.

\section{References}

[1] Murphy, K.L. and Y. Gazi, "Role plays, panel discussions and simulations: Project-based learning in a web-based course." Educational Media International, 2001. 38(4): p. 261-270.

[2] Lou*, Y., "Learning to solve complex problems through between - group collaboration in project - based online courses." Distance education, 2004. 25(1): p. 49-66.

[3] Duerig, T., A. Pelton, and D. Stöckel, "An verview of nitinol medical applications". Materials Science and Engineering: A, 1999. 273: p. 149-160.

[4] Parsai, E.I., A. Jahadakbar, H. Lavvafi, and M. Elahinia, "A novel and innovative device to retract rectum during radiation therapy of pelvic tumors." Journal of applied clinical medical physics, 2019. 20(1): p. 194-199.

[5] Jahadakbar, A., M. Nematollahi, K. Safaei, P. Bayati, G. Giri, H. Dabbaghi, D. Dean, and M. Elahinia, "Design, Modeling, Additive Manufacturing, and Polishing of Stiffness-Modulated Porous Nitinol Bone Fixation Plates Followed by Thermomechanical and Composition Analysis". Metals, 2020. 10(1): p. 151.

[6] Amerinatanzi, A., H. Zamanian, N. Shayesteh Moghaddam, A. Jahadakbar, and M. Elahinia, "Application of the superelastic NiTi spring in ankle foot orthosis (AFO) to create normal ankle joint behavior." Bioengineering, 2017. 4(4): p. 95.

[7] Jahadakbar, A., N. Shayesteh Moghaddam, A. Amerinatanzi, D. Dean, H.E. Karaca, and M. Elahinia, "Finite element simulation and additive manufacturing of stiffness-matched NiTi fixation hardware for mandibular reconstruction surgery." Bioengineering, 2016. 3(4): p. 36. [8] Tan, C, Li, S., Essa, K., Jamshidi, P., Zhou, K., Ma, W., and Attallah, M.M., "Laser powder bed fusion of Ti-rich TiNi lattice structures: Process optimization, geometrical integrity, and phase transformations." Int. J. of Machine Tools and Manufacture., June 2019; 141:19-29.

[9] Saghaian, S.E., Moghaddam, N.S., Nematollahi, M, Saedi, S., Elahinia, M, and Karaca, H.E., "Mechanical and shape memory properties of triply periodic minimal surface (TPMS) NiTi structures fabricated by selective laser melting." Biology, Engineering and Medicine, 2018, Vol. 3(5):1-7.

[10] Pelton, A., T. Duerig, and D. Stöckel, "A guide to shape memory and superelasticity in Nitinol medical devices." Minimally Invasive Therapy \& Allied Technologies, 2004. 13(4): p. 218-221.

[11] Elahinia, M.H., Shape memory alloy actuators: design, fabrication, and experimental evaluation. 2016: John Wiley \& Sons.

[12] Nemat-Nasser, S. and W.-G. Guo, "Superelastic and cyclic response of NiTi SMA at various strain rates and temperatures." Mechanics of Materials, 2006. 38(5-6): p. 463-474. [13] Andani, M.T., F. Bucchi, and M.H. Elahinia, "SMA actuation mechanisms." in Shape Memory Alloy Actuators: Design, Fabrication and Experimental Evaluation, 2015. pp. 85. 